EDUCATION AND DEBATE

\title{
A literature and medicine special study module run by academics in general practice: two evaluations and the lessons learnt
}

\author{
L Jacobson, A Grant, K Hood, W Lewis, M Robling, H Prout, A M Cunningham
}

J Med Ethics; Medical Humanities 2004;30:98-100. doi: 10.1136/jmh.2004.000176

This paper describes the design, delivery and evaluation of a nine week special study module on literature and medicine for third year undergraduate medical students, by tutors from an academic department of general practice. Three weeks of taught seminars are followed by three weeks of one on one meetings between individual students and tutors, leading to a seminar led by, and based on, materials prepared by the student. The final three weeks of the course are dedicated to completion of essays about areas chosen by students for in depth study. The course was evaluated on two separate occasions, using two different techniques: the first evaluation used a focus group technique to identify and explore relevant themes; the second used nominal group theory to assess whether the course worked educationally, and how it could be improved.

In the main, the course was judged to meets its aims, with generally positive student comments, albeit with caveats and reservations. The subject matter was intellectually challenging for students and tutors. Further research into the optimal size for such groups, and a more formal evaluation of tutors' experiences is required.

See end of article for authors' affiliations

Correspondence to: L Jacobson, Department of General Practice, University of Wales College of Medicine, Llanedeyrn Health Centre, Llanedeyrn, Cardiff CF23 9PN; jacobson@cf.ac.uk
A n optional special study module (SSM) in literature and medicine has been offered by tutors from the department of general practice at the University of Wales College of Medicine since 2000. The inspiration for the course came from a conference presentation of a similar course run by the department of general practice at the University of Birmingham. ${ }^{1}$

This paper provides an overview of the educational objectives for the course as well as details of some of the seminars. The course was evaluated on two separate occasions, using two different techniques: the first evaluation used a focus group technique to identify and explore relevant themes; the second used nominal group theory to assess whether the course worked educationally, and how it could be improved. Details of these evaluations are provided and compared with evaluations of similar SSMs conducted elsewhere. ${ }^{1-6}$

The course has had eight students in each of the four years to date, and has so far used 11 teachers. None of the tutors have any great expertise in the field of medical humanities, but all have shown great interest in the course, and have been enthusiastic participants. All were keen to assess how the students viewed the course, and how and whether "it worked".

\section{COURSE DESIGN}

The course involves nine full weeks of study, and is divided into three phases of three weeks each. The first comprises compulsory seminars with the eight students and two tutors. The second comprises tutorials with individual students and their tutor in preparation for their student led seminar, and in the final three weeks the students prepare assessed essays.

\section{EDUCATIONAL OBJECTIVES}

The principal aim of the course is to enhance student understanding of the experience of illness and disease through the study of literature and other popular media. Other aims include an examination of lay perceptions of illness and disease; an examination of representations of doctors in literature and other popular media such as TV and film; the provision of an opportunity for students to reflect on how others may view them in their professional role, and the fostering of a patient centred understanding of illness.

\section{SEMINARS}

Examples of seminars are given in box 1. Led by one tutor with an interest in a certain area, and cofacilitated by a second tutor, the content of the seminars has evolved with students adding to the body of work available for discussion. In 2002 two seminars, using a technique known as "reflective/automatic writing", whereby the students reflect on aspects of the medical course as a whole, and the SSM in particular, were added. The writing was conducted in silence, and ensuing discussion focused on any aspects "discovered" during the process of writing-that is, ideas, memories or feelings that the writer only becomes aware of as a result of the act of writing. The sessions sought to demonstrate to the students both that they were capable of creative writing, and that creative writing can facilitate constructive reflection upon medical practice. $^{7}$ The therapeutic value of creative writing was also discussed.

Abbreviations: NGT, nominal group technique; SSM, special study module 


\section{Box 1: examples of seminar subjects ${ }^{8}$}

- An introductory seminar features a short story by Ernest Hemingway, and an autobiographical piece by a drug addict in prison.

- A seminar entitled "Ethics" discusses an excerpt from some autobiographical journalism by John Simpson, and the film, One Flew Over the Cuckoo's Nest.

- A seminar entitled "Cancer" features autobiographical work by John Diamond and Ruth Picardie.

- An all day seminar, involving a visit to a now closed South Wales coal mine, is intended to place in context references to The Citadel by A J Cronin, which is set in a South Wales mining community.

\section{TUTORIALS}

Each student was assigned a tutor who helped the student focus on an area of specific interest to him or her. Some examples of subjects chosen are provided in box 2 . Tutorials took place weekly to allow student and tutor to discuss texts or other cultural media thought salient. This required some reading or review of cultural media by the tutor to allow shared discussion to take place. This was particularly appropriate if the student had found unusual or unfamiliar material.

\section{STUDENT LED SEMINARS}

In week six, each student, supported by their individual tutor, led a seminar involving the other students and a second non-participant tutor, on their chosen area of study, and allowed the group to help in the development of the topic. These seminars lasted up to two hours. Each student was given verbal feedback about their presentational and facilitation skills by the tutors and by their peers using sensitive, non-threatening feedback techniques. This feedback did not contribute to the final mark.

\section{ASSESSMENT}

The students prepared a 6000 word assessed essay on their chosen subject in the final three weeks. To date, the essays have all easily achieved the requisite marks to pass the course. One essay has been of sufficiently high standard to be published. ${ }^{9}$

\section{EVALUATIONS}

Two evaluations of the course have been undertaken to provide feedback for tutors and to enable course development. This was particularly important because the teaching was novel to the tutors, and they wanted to find out whether the students felt the course had offered a valuable learning experience. Students were also asked if they had any comments on the tutors' qualifications to teach this course.

\section{Box 2: examples of subjects chosen by students}

- The representation of addiction in the lyrics of Alice in Chains

- Medical students and dissection

- Medicine as pantomime

- Doctors as addicts

- The poetry of Sylvia Plath and depression

- The grieving process as seen by adolescents
The first evaluation, undertaken in 2000, involved focus group discussions before and after the module, with all of the students for that cohort taking part. Two researchers (MR, HP) who were not otherwise involved in the SSM facilitated the discussions. The focus groups lasted one hour. Salient themes were recorded and analysed using a grounded theory approach. ${ }^{10}$ The first focus group explored student expectations about how the course might help them learn. The second evaluation, undertaken in 2002 and using nominal group technique, investigated whether students' expectations had been met. ${ }^{11}$

\section{RESULTS OF EVALUATIONS}

\section{Focus groups from 2000}

Some of the key themes emerging from the focus group discussions are presented below. The order of presentation does not reflect the relative importance placed on these points by participants.

\section{Break from standard curriculum}

The students commented on their enjoyment of reading and hoped the course would allow opportunities to read for leisure again. They felt the course would benefit from being self contained, that is with no members of non-medical departments involved. At the second meeting, they reported that the SSM had indeed allowed them to read for leisure, and that this had been a refreshing and positive experience.

\section{Personal and professional development}

At the first meeting, the group hoped the SSM would allow opportunities to broaden horizons, to see things from a different point of view, to learn to accept other peoples' thoughts and feelings, and to be able to converse on nonmedical topics. At the second meeting, the group confirmed these wishes had been met.

They also mentioned that the course had allowed opportunities to construct arguments while seeing other perspectives, and to improve their organisational and critical thinking skills. They commented upon their general growth and self development, and upon an attitudinal change when considering how they would interact with patients in future.

\section{The format of the course}

The students commented that the small group format facilitated the process of learning, providing a useful means to discuss troubling issues. It was acknowledged that this format could sometimes make it difficult to discuss personal thoughts or convictions. The students found the one to one tutoring helpful, and commented favourably upon the less didactic methods of supervision involved. They enjoyed the self directed learning, and made no specific comments on the lack of overt literary criticism within the course, or upon tutors' overall knowledge.

\section{Disadvantages, controversies, and suggestions}

Students found it difficult to know what supervisors expected from the essays and they requested more guidance. Interestingly, they were keen for the individual student led seminars to be formally assessed. They also wanted more group meetings in the latter part of the course. They suggested advising future students to watch a film in its entirety before discussing clips during the seminars, and placing the visit to the coal mine in the middle of the course. These suggestions were acted upon for subsequent years.

\section{Nominal group technique from 2002}

The nominal group technique (NGT) meeting took place on the morning of the penultimate day of the 2002 module, with all students willing to take part. The meeting was conducted solely by AG, and lasted one hour in total. AG guaranteed 
Table 1 Issues ranked in order of importance to participants

\begin{tabular}{ll}
\hline - Allowed to metaphorically experience illness & 14 \\
situations we wouldn't otherwise experience & 13 \\
- No need to timetable student only meetings & 13 \\
- really enjoyed automatic writing - should have been & 11 \\
- Tutor should have been assigned earlier to help & \\
choose topics & 9 \\
- Would have preferred more short stories and & \\
books than extracts & 9 \\
- Could have trip to Hay Literature festival & 8 \\
- It affected me as a person, and then as a doctor & 6 \\
- $\begin{array}{l}\text { Allows you to think about topics you might not have } \\
\text { previously thought about }\end{array}$ & 5 \\
- Would have been useful to have experts from \\
English department
\end{tabular}

that comments could not be ascribed to individual students. At the beginning, the students were asked to complete responses to two questions: "In what way do you think the SSM will help your future in medicine", and "In what way could the SSM have been improved". Their responses were to be written down in silence for the first five minutes of the seminar.

In the second phase, all students were asked in turn to read out their first responses, which were written on a flipchart by AG, without discussion at this stage. This process was repeated until no new responses were forthcoming. In the third phase, AG and the students reassembled the list to allow for any overlap. Finally, each student was allowed five votes with "scores" of five reflecting most important, going down to one as their least important vote. Each student in turn cast their vote, until all 120 potential votes for important issues were cast. The results of this voting schedule, indicating the main issues (representing 111 votes) are shown in table 1 .

\section{DISCUSSION AND OVERALL REFLECTIONS}

The 32 students who have been involved in this course so far appear to have gained from the experience. The data from both evaluations indicate that the primary aim of our course has been met with both groups of students indicating a resultant increase in their broader understanding of the illness and disease experience. The item that received most votes in the NGT, that is that the course had allowed them to metaphorically or imaginatively experience illness situations they would not otherwise of experienced, specifically relates to the broad aim of the course. Further, the use of automatic writing was welcomed by students who both enjoyed the course and appreciated the opportunity to think about topics which they might otherwise not have considered.

It is of particular interest that both groups indicated enhanced personal growth and development as a result of the course. This is similar to findings reported from Oxford, ${ }^{6}$ and from Newcastle where students reported that much of their reading has personal rather than professional benefits. ${ }^{12}$ The NGT group reinforced these findings, with students indicating that the course affected them as people first, and then in their professional role.
It is the view of the authors that the SSM would not translate well to a larger, lecture based, didactic experience. This sense of maintaining a proportion for such courses has been discussed before, and the SSM can be said to have embraced the main principles of such a course by being small and group based. ${ }^{36}{ }^{14}$ It is the authors' belief that the size of the group plays a key role in facilitating the learning experiences described in this paper.

Less positive student responses include concerns about the difficulty in assessing tutor expectations, and issues of course ownership, such as the relative value placed upon students' and tutors' opinions, and the sources of literature used. It is also of note that the NGT group indicated they would have preferred some involvement from non-members of the department.

Tutors appear to enjoy developing, running, and evaluating the course although this has not been formally evaluated. Most tutors have expanded their own reading, especially as a result of their role as individual tutors and also as a result of assessing student essays. ${ }^{2}$ This learning provided a useful adjunct to the tutors' personal development, both as professionals and as teachers. ${ }^{13} 15$

Tutors have made little comment on the difficulties of marking subjects on which they have previously had little expertise. The authors of this paper hope that our present combination of enthusiasm and interest will allow this course to continue to provide students with a valuable and relevant educational experience while we, as tutors, gain in experience and lose some of our original naivety. We hope that we too will continue to be "stretched".

\section{Authors' affiliations}

L Jacobson, A Grant, K Hood, W Lewis, M Robling, H Prout, A M Cunningham, Department of General Practice, University of Wales College of Medicine, Cardiff, UK

Accepted 10 September 2004

\section{REFERENCES}

1 Skelton J, Thomas C, Macleod J. Teaching literature and medicine to medical students. Part 1. The beginning. Lancet 2000;356:1920-2.

2 Calman K, Downie R, Duthie M, et al. Literature and medicine: a short course for medical students. Med Educ 1988;22:265-9.

3 Downie R, Hendry R, Macnaughton R, et al. Humanising medicine: a special study module. Med Educ 1997;31:276-80.

4 Kirklin D, Meakin R, Singh S, et al. Living with and dying from cancer: a humanities special study module. J Med Ethics: Medical Humanities 2000;26:51-4.

5 Glasser B. From Kafka to Casualty: doctors and medicine in popular culture and the arts - a special studies module. J Med Ethics: Medical Humanities 2001;27:99-101.

6 Lancaster L, Hart R, Gardner R. Literature and medicine: evaluating a special study module using the nominal group technique. Med Educ 2002;36: 1071-6.

7 Bolton G. Reflective practice. London: Sage, 2001

8 Medical Humanities website: http://www.mhrd.ucl.ac.uk/cgi-bin/ c-showdetails? ID = 148 (accessed 29 October 2004).

9 Francis N, Lewis W. What price dissection? Dissection literally dissected. J Med Ethics: Medical Humanities 2001;27:2-9.

10 Strauss A, Corbin J. Basics of qualitative research: techniques and procedures for developing grounded theory [2nd ed]. Thousand Oaks, CA: Sage, 1998.

11 Lloyd-Jones G, Thomas M, Bligh J. The use of the nominal group technique as an evaluative tool in medical undergraduate education. Med Educ 1999;33:8-13.

12 Hodgson K, Thomson R. What do medical students read and why? A survey of medical students in Newcastle upon Tyne. Med Educ 2000;33:622-9.

13 Smith B, Taylor R. Medicine-a healing or a dying art? Br J Gen Pract 1996:46:249-51

14 Macnaughton J. The humanities in medical education: context, outcomes and structures. J Med Ethics: Medical Humanities 2000;26:23-30.

15 Donley C, Kohn M. Literature and medicine [appendix c]. In: Wedding D, ed. Behavior and medicine. St Louis, MO: Mosby, 1995:507-13. 